(02017, Elsevier. Licensed under the Creative Commons Attribution-NonCommercialNoDerivatives 4.0 International http://creativecommons.org/about/downloads 


\title{
Diagnosing Capabilities in Family Firms: An Overview of Visual Research Methods and Suggestions for Future Applications
}

\author{
Alice Comi \\ University of Reading, Design Innovation Research Centre \\ Martin J. Eppler \\ University of St. Gallen, Institute of Media and Communications Management
}

\begin{abstract}
Family firms often develop unique capabilities over time, but these organizational competencies are difficult to identify, isolate and describe independently of the key individuals in the family firm. In this article, we provide examples and an overview on research methods that can be used to identify and visualize organizational competencies in family firms. We report from pilot applications of such visual competence diagnostics in an action research mode. We structure our article as follows: We first show the relevance of the competence visualization topic for family firms. In a second step we classify available methods for competence visualization in a simple framework. In a third step, we report on our experience on researching a family firm with the help of visual competence diagnostics methods. We conclude the article with implications for family firm researchers and practitioners and provide a brief outlook on visual research methods and their role in better understanding family firms.
\end{abstract}

Keywords: family firms, competence visualization, visual methods, action research, competence diagnostics

This is the Authors' accepted manuscript for self-archiving purposes. Please refer to the final publication on Elsevier's website for pages and citation. The final publication is available on:

http://dx.doi.org/10.1016/j.jfbs.2014.01.009 


\section{Diagnosing Capabilities in Family Firms: An Overview of Visual Research Methods and Suggestions for Future Applications}

\section{Introduction}

In his seminal review of the state-of-the-art of family business strategy research, Astrachan (2010, p. 8) identifies as one of ten fruitful and needed research areas the question of how to best "leverage the resources and competitive capabilities of family businesses." This seems a particularly relevant area of research when family businesses undergo a major transition such as when they face a succession (Cabrera-Suárez, De Saá-Pérez, \& García-Almeida, 2001). As Cabrera-Suárez et al. (2001) have pointed out, one of the main challenges of succession in family firms is the difficulty of acquiring the predecessor's key knowledge and skills adequately to maintain and improve the organizational performance of the firm. By informing decisions of knowledge exploitation versus exploration, the diagnosis of competences can mitigate the problem of organizational inertia typical of family businesses (Webb, Ketchen Jr, \& Ireland, 2010). As explained by Chirico and Nordqvist (2010), family businesses often lose their competitive edge as founders become unwilling to undertake the risks of entrepreneurship and become trapped in a tendency to over-exploit existing competences. More broadly, the resource-based view has the potential to sustain the competitiveness of family businesses, by assisting the identification of resources and capabilities to be developed internally or acquired externally (Mazzi, 2011). The resource based view also promises to be one of the most fruitful research paradigms to study the idiosyncrasies of family firms and to develop a sound and distinct theory of family firms and their strategizing (Chrisman, Kellermanns, Chan, \& Liano, 2010; Mazzi, 2011, p. 167).

Our article addresses this challenge from a research methods perspective and provides an overview of visual methods for competence diagnostics, a framework for their use, and an application experience from the family firm context. More specifically, we propose a methodological approach enabling family businesses to perform - with the help of researchers - competence identification and management (either individually or through strategic alliances). With a clear understanding of the architecture of their competences, family firms can then make informed decisions as to how to further develop their capabilities, or to acquire new ones. With this contribution we thus hope to enable family firm researchers to follow Astrachan's (2010, p. 8) call for more resourceand knowledge-based research on family firms that is empirically grounded. The resource-based view in fact is at the very core of the concept of "familiness" (Habbershon, Williams, \& MacMillan, 2003; Habbershon \& Williams, 1999), defined as the unique bundle of resources developed through interaction between the family business, its individual members and competitive environment (Sirmon \& Hitt, 2003). We believe that competence visualization methods can be instrumental in surfacing the key elements that constitute such familiness; for example by making explicit the competences that are at the roots of the business. To this end we first outline the relevance and the challenges of competence management for family businesses in the next section. We then systematically review existing approaches to identify (in section 3) and map (in section 4) organizational competencies. In section 4 we also summarize existing approaches through a simple classification and an organizing framework. We present a real-life illustration of how researchers can employ such methods (in section 5) and describe pitfalls to avoid in this process. In section 6 we derive implications for family business researchers and discuss limitations and development needs of organizational competence mapping approaches for the family business context.

\section{Challenges of competence management for family businesses}

Family businesses are an important source of economic development and growth, as their long-term nature is uniquely suited to sustain the allocation of resources for innovation and risk tak- 
ing (Zahra, Hayton, \& Salvato, 2004). In spite of their importance, most family businesses do not have a long-term strategic plan due to the lack of time, inadequate knowledge of the planning process, or reluctance to share strategic plans with external consultants (Sharma, Chrisman, \& Chua, 1997). Furthermore, most of the strategy literature and research methods do not specifically address the resource needs and constraints of family businesses, but have been developed for the skills and resources of large non-family enterprises (Sharma et al., 1997).

Yet having a consistent and clear strategy is essential for the success of family businesses (Astrachan \& Kolenko, 1994). It is critical that family business managers develop a strategy plan to sustain competitive advantage over time and to ensure the long-term survival of their businesses. Key to strategic planning is the ability of a company to identify and strengthen its core competences. Core competences are those activities that a firm performs better than any other competing firm (Prahalad \& Hamel, 1990). As further explained by Prahalad (1993, p. 45), core competencies result out of the "creative bundling" of multiple technologies, customer knowledge and intuition; combined and managed as a harmonious whole. Without an understanding of their competence structure, family businesses may continue to do "business as usual" in a shifting landscape and become unsustainable in the future. As they rarely have all the resources to compete effectively, family businesses can either develop new skills internally or tap into their external networks (Sirmon \& Hitt, 2003). The latter brings along additional challenges such as identifying the appropriate partners or integrating and rationalizing strategic resources and skills. Strategic alliances, in particular, are risky endeavors for family firms, and failure may be particularly consequential for SMEs, where in-house resources are stretched to the limit (Baum, Calabrese, \& Silverman, 2000; Narula, 2004).

As further explained by Sirmon and Hitt (2003), managers of family businesses should continuously evaluate their resource and capability inventory, and carefully make decisions as to the addition, and at times, shedding of resources. Yet family firms' managers are often unlikely to make appropriate shedding decisions, "due to the emotional ties, nostalgia and/or escalation of commitment related to their unique social and human capital" (Sirmon \& Hitt, 2003). While resource accumulation is important to ensure growth, resource shedding can be extremely important for resource-constrained firms, by reducing the opportunity costs of maintaining inferior resources. Besides releasing financial capital and reducing costs, shedding resources can also break path dependencies, therefore addressing the problem of organizational inertia typical of family business. The socalled "family inertia" (Chirico \& Nordqvist, 2010, p. 4) is particularly detrimental for preventing the development of dynamic capabilities of renewing the organization to better suit the changing environment.

After the stage of development or acquisition, resources and capabilities should be bundled and leveraged through an appropriate strategy designed to achieve a sustainable advantage (Sirmon $\&$ Hitt, 2003). To do this effectively, family firm managers must integrate opportunity and advantage-seeking behaviors in an appropriate strategic plan, which utilizes resources effectively and creates wealth (Le Breton-Miller \& Miller, 2006). As explained by Le Breton-Miller and Miller (2006), the strategic plan should leverage the unique features of family businesses, such as concentrated ownership, lengthy tenures, and business expertise. If tied to the value chain, such features are likely to engender competitive asymmetries, i.e. organizational qualities that are difficult for other firms to imitate. At the same time, investments in enduring partnerships enhance access to resources and free family firms from the burden to develop additional skills. And the commitment to a compelling mission is instrumental to turn unique features and external resources into a core competency. Yet bundling and leveraging resources and capabilities in such a way requires a set of mixed and diverse managerial skills that may not naturally reside in family businesses (Sirmon \& Hitt, 2003).

Competence development is therefore a key part of the general business strategy of family firms. An empirical exploration of SMEs in the European Union (Snijders, van Lin, \& van der Horst, 2003) indicates that involvement in competence development activities has a positive effect on SME competitiveness and performance. Without the ability to continuously analyze their inter- 
nal and external environment and adjust their strategic goals and plans accordingly, small enterprises and family businesses run the risk of lagging behind, instead of pro-actively tackling market changes. However, such businesses are particularly at a disadvantage in performing competence diagnostics, as they typically suffer from a number of obstacles (Snijders et al., 2003), which include:

- Limited time to take a strategic, long term approach to identifying and maintaining core competences due to short-term business pressures

- Limited time to map the company's core competences to its existing markets and diagnose effectively their own competence needs

- Limited time or expertise to identify new core competences required to allow the company to expand to new markets or develop new products

- Cost (constraints) issues

- The management team's limited contact with other external sources of competences

These limitations can significantly reduce the speed at which family firms respond to competitive pressures and hamper their future growth. By having a clear picture of the competence structure of their family businesses, managers could make more informed choices as to which resources they should leverage in order to address competitive pressures and sustain future growth. Visual research methods have been applied to a range of complex organizational processes (e.g., organizational change) in that they are suitable to get access to deeper and unarticulated knowledge (Meyer 1991). This article applies visual methods for researchers to assist family businesses in the identification and management of competences in an action research mode. As suggested above, family businesses have an urgent requirement for easy to use, time efficient but comprehensive management tools to help them identify their competences and understand their underlying activities, resources, and coordination mechanisms. In addition, these tools may provide family business researchers with a relatively simple research approach that is compatible with the constraints and needs of family business practitioners who serve as research subjects. We believe that the adoption of visual research methods in the context of one-to-one interviews is particularly suitable for researchers to understand the competence structure of family businesses. In turn, the adoption of such methods can benefit family businesses by sustaining competence identification, and informing competence development in an action research mode. The visualization process facilitated by the researcher can also help family business owners reduce their emotional connotation of resources and assist them in making more rational disinvestment or investment decisions. Before we present such visual approaches, we first clarify the key concepts in this field (such as the notion of core competence), evaluate the current approaches to identify organizational competencies, and show the need for competence mapping approaches when researching family firms.

\section{Current approaches to organizational competence identification}

First introduced by Prahalad and Hamel (1990) on the background of the resource-based view of the firm (Penrose, 1995), the competence perspective has received widespread attention in the strategic management literature. This perspective advocates the coordination of tangible and intangible resources to generate valuable, inimitable, rare, and non-substitutable competences that lead to sustainable competitive advantage. A core competence is defined as the collective learning of an organization, providing the glue that binds together existing businesses, and the engine for new business development (Prahalad \& Hamel, 1990). Furthermore, core competences are the roots of competitive advantage, in that they are resistant to imitation, central to customer value, and conducive to market penetration. Understanding the competence structure of the organization is thus an essential requirement whether a company is seeking to change its boundaries, facing threats, or aligning resources with goals (Mills, Platts, Bourne, \& Richards, 2002). As further recommended by Prahalad and Hamel (1990), managers should develop a strategic architecture for competence 
building, by drawing a roadmap of the future that identifies which core competencies to build and their underlying resources.

Yet the identification of (core) competences can be quite difficult due to the vagueness of the theoretical construct. The competence concept in fact remains at an abstract level, leaving practitioners without clear guidance for the application stage (Javidan, 1998; Klein, Gee, \& Jones, 1998; Mills et al., 2002; Tampoe, 1994; Walsh \& Linton, 2001). Clark (2000) and Vaitkevičius (2006) further suggest that small businesses have a tendency to approach competence identification from an informal perspective, and lack the instruments to develop their strategic architecture. Thus, several scholars have attempted to compensate for the elusiveness of the competence concept, by developing practical methods to assist management in the identification and development of core competences in agreement with the company strategy. In their work on using core competences to develop new business opportunities, Bakker, Jones, and Nichols (1994) introduced an identification method based on observing the company, naming competences, and obtaining customer and expert evaluation of these competences. In an attempt to link competences to company goals, Eden, Williams, Ackermann, and Howick (2000) outlined a method which builds on listing order winners and existing competences, to be connected via the use of group support systems and causal maps. These methods are more of a general outline built upon the ability of management, industry experts, and external observers to name competences, rather than a formal and sustainable analytical process. They also lack detailed steps and tools for implementation, and focus more on the evaluation of already identified competences rather than on discovering competences and analyzing their underlying activities and resources.

Marino (1996) described a more detailed method for developing consensus around the core competences of an organization. The process starts from tangible products, identifies the sources of competitive advantage, nominates competences, and reduces this list to 2-5 core competences on which consensus is reached by the management team. In a similar attempt to exploit the core competences of companies, Tampoe (1994) advocated for a reverse engineering approach which starts with end products and decomposes them in order to identify core competences. Gallon, Stillman, and Coates (1995) outlined a modular approach which starts by nominating a work team, defining strength and capability measures, constructing an inventory of capabilities, and isolating core competences. Although more detailed than the processes suggested by Bakker et al. (1994) and Eden et al. (2000), these methods assume that competences will make themselves "apparent" once core products are identified, and are built on the existence of a competence-literate management teams. Besides, these studies also lack the tools for facilitation, and employ evaluation methods that deliver highly aggregated competences, with no reference to underlying activities, resources, and coordination mechanisms. This leads to a risk of theorizing what is not grounded in empirical facts.

In the attempt to fill the resource analysis gap, Lewis (1995) suggested to start with an activity mapping exercise, to evaluate activities by assessing performance against importance, to generate the resources underlying these activities, and to identify strategic resources. The activities that provide competitive advantage over competitors, and build on strategic resources are considered as being core competences. This process considers the resource base and employs tools for generating data; it however creates a large amount of data and requires heavy facilitation to derive the information, create individual maps, and carry out an analysis for group review. Another attempt to create a competence identification process is that of (Javidan, 1998) which starts by naming a company's "know-how", and identifies core competences as "know-how" which spreads across the corporation. This process again assumes that managers can easily name competences without an analysis process (and without any stimuli to do so), and is better suited for larger corporations since it differentiates core competences on the basis of their spread throughout the corporation.

A fixed list of 22 intangible resources was used by Carmeli (2004) in an attempt to assist companies in understanding their core intangible resources. Company managers are asked to nominate the top seven resources that apply to their business, and evaluate them on the basis of "value", "rareness", "inimitability", "and "non-substitutability". The fixed list approach was also used by 
(Yang, Wu, Shu, \& Yang, 2006) who developed a list of competences for analyzing the company from an activity, process, and functional perspective in order to gain a deeper understanding of core competences. The results are fed into a large database that establishes relations, and derives insight into core competences, and their perception throughout the company. Yet the assumption that a fixed list of (relatively abstract) competences can be used to explore and evaluate core competences ignores the idiosyncratic nature of competences, especially intangible ones, and delivers a generic competence list that is difficult to translate into competitive advantage. It may also be difficult for family business managers to relate to these categories, and thus for family business researchers to employ them as response triggers in their analyses of family firms.

King and Zeithaml (2001) and Walsh and Linton (2001) also proposed a listing approach to competence identification, based essentially on comparing organizational competences against a list of industry-relevant competences. King and Zeithaml (2001) suggested a three-steps approach built on listing competences valuable to the industry, a self-evaluation of the company in relation to these competences, and finally communication of results throughout the company. Walsh and Linton (2001) proposed that industry experts generate a detailed list of industry-relevant competences, classified into managerial (knowledge-embedded and knowledge-based) competences and technical (fabrication, assembly and material) competences. Then, the management rates the company against the industry competence list, and checks if absent competences are necessary and obtainable. Both these methods assume that industry competences are homogeneous, and overlook the fact that companies win orders on their distinctive competences and skills, even though they may compete in the same industry. Besides, the checklist approach is long and time consuming, neglects the idiosyncratic nature of competences, and fails to provide detailed analysis steps and tools for deriving them.

Mills et al. (2002) observed a link between the objective behind competence identification and the identification process employed. They introduced two methods for identifying competences on the basis of analysis depth. The "Awareness" method is intended to establish quick links between objectives and resources, and builds on the breakdown of business objectives into change and improvement activities which are further analyzed to identify underpinning resources. The "Insight" method was suggested for a deeper resource analysis; it builds on naming the scope of the analysis, identifying the major activities within this scope, and tracing the history of company activities to identify underlying resources. Both processes are highly dependent on the management team's ability to predict necessary activities, and are geared towards enabling managers to make resourceaware decisions, rather than understanding underlying competences. In particular, the "Insight" method delivers a set of compound resources with no indication as to how they are coordinated to deliver a particular competence.

While making a first step towards understanding the competence structure of a company, all of the above methods suffer from the following drawbacks which are particularly problematic in the family firm research context:

- A tendency to list competences rather than analyze current company activities to identify competences;

- A lack of linkage between the resources underlying competences, and the coordination mechanisms responsible for delivering competences;

- A tendency to be time consuming, requiring competence literacy, and be geared towards large corporations rather than small and family businesses.

In the next section, we advance the view that the use of visual frameworks for competence mapping in the context of action research with family firms reduces the elusiveness of the competence concept, and assists researchers and managers in identifying the competence structure of a family business. We provide an overview of competence templates available to researchers and managers; and we illustrate their use in an action research aimed to assist a family business in managing the succession stage (in section 4). 


\section{Organizational Competence Visualization Methods}

Although visual research methods still have to gain momentum in many areas of management research (Bell \& Davison, 2013), the use of visual representations can assist the identification and management of organizational competences. With the term visual representations, we refer to diagrammatic representations of organizational competences, produced in the context of the encounter between researchers and practitioners, most notably in one-to-one interviews. Such interviews generally take place in the context of "action research", a form of engaged scholarship in which the researcher sets out to investigate complex problems with, and to the advantage of practitioners (Van de Ven, 2007). The underlying rationale for action research is that scholars are more likely to produce knowledge advances that are both scientifically and practically relevant when they interact and learn with practitioners. This approach has the potential to stimulate dialogue between management science and profession; and hence to improve the quality of problem formulation, theory building, research design and implementation.

A variety of benefits can be associated with the use of visual representations, for example, in the context of action research concerned with assisting the overall process of competence management in a family business. First, visual representations can facilitate competence identification, and ultimately contribute to the constitution of 'organizational self-knowledge' (Rulke, Zaheer, \& Anderson, 2000), by increasing managers' awareness of their businesses' competences. Visual representations in fact can assist the elicitation of tacit knowledge and clarify the connections among organizational competences and resources (Mills et al., 2002). In addition, visual representations can promote a shared understanding of competences, by acting as "boundary objects" across individual, functional and organizational boundaries (Carlile, 2004). Visual representations also allow for reviewability and revisability, thus facilitating the collective refinement of the competences elicited in the research encounter (Bresciani \& Eppler, 2009). By re-examining arguments with the use of visual frameworks, researchers and managers can build common ground, and ultimately achieve a co-constructed understanding of organizational competences. This allows researchers to construct theories that are more solidly grounded in (and more accurately represent) the reality of family business practitioners.

Besides facilitating competence identification, visual representations can assist competence management, with particular regard to the process of aligning core competences with the organization's strategy. As an example, the competence tree by Sawyer and Gammack (2006) represents operational and core competences in a hierarchical connection to the corporate vision, and to the success factors in a competitive domain. Competence visualization can also support the competence agenda by directing the exploration of novel competences, and guiding the exploitation of existing competences. In this regard, the core competence agenda matrix by Torkkeli and Tuominen (2002) relates novel and existing competences with novel and existing product markets. By assisting competence planning, visual representations help to avoid 'competence traps', defined in terms of a dysfunctional imbalance between knowledge exploration and exploitation (Liu, 2006). Furthermore, visual representations can facilitate the decision about whether to enter into a strategic alliance, by enabling managers to foresee competence complementarities with the prospect partner.

In searching across the domains of strategic management, technology management, and knowledge management, we have identified a total of twelve frameworks with substantial applicability to competence management in family businesses. Since a detailed review of the collected frameworks is beyond the scope of the present article, an attempt is made to provide a general overview of competence visualization, by introducing a simple overview classification (Table 1). We have developed this classification in order to identify the building blocks of competence visualization. The classificatory dimensions capture the fundamental components of competence visualization, and converge to define a tentative ontology of this domain. As an organizing principle for this overview, we use the three main interrogatives of what, how, and why. 


\begin{tabular}{|c|c|c|}
\hline What? & How? & Why? \\
\hline Core competence & Hierarchical & Identification \\
\hline Competence & Supportive & Development \\
\hline Supportive competence & Temporal & Allocation \\
\hline Operational competence & Matching & \multicolumn{2}{|c}{} \\
\cline { 1 - 2 } Resources & \multicolumn{2}{|c}{} \\
\cline { 1 - 2 } & &
\end{tabular}

\section{Table 1: Classification of competence visualization elements}

The what dimension refers to the content represented in a competence visualization. In particular, core competence is the collective knowledge of an organization, essential to the implementation of a strategic vision, and critical for long-term survival (Prahalad \& Hamel, 1990; Tampoe, 1994). By contrast, a competence is functionally-based, and represents 'ordinary' knowledge which contributes to organizational success, although without being conducive to sustainable advantage per se (Mills et al., 2002; Tampoe, 1994). A supportive or dynamic competence is meta-knowledge with the potential to enhance ordinary competences, with applicability to a wide range of organizational activities (Mills et al., 2002; Winter, 2003). Finally, operational competence (or skill) is procedural knowledge with reference to a series of processes and routines whereby the organization coordinates the interaction among resources (Javidan, 1998; Torkkeli \& Tuominen, 2002). In this context, resources represent the building blocks of organizational competences, and include tangible resources such as plants, technology, and equipment, as well as intangible ones, such as culture, values, and beliefs (Mills et al., 2002).

The how dimension refers to the coordination mechanisms whereby the objects represented within a competence representation - either competences or resources - are connected into meaningful relations. The visual framework may underline hierarchical relations, linking competences via vertical and horizontal connections in a pyramidal or tree-shaped structure (Mills et al., 2002; Sawyer \& Gammack, 2006; Walsh \& Linton, 2001). Alternatively, the competence graphic may represent supportive relations, e.g. by depicting competences as a series of interlinked nodes, forming a network structure (Klein et al., 1998). The competence visualization may emphasize the temporal dimension, by relating competences either in a linear, or in a cyclical manner. For example, Pietroforte (1996) portrays competences in a linear relation along the value chain, while Marti (2004) depicts a reinforcing cycle between customer analysis, individual competences, core competences, and financial results. A competence visualization may represent matching relations, supporting the connection of relevant elements to facilitate the generation of new insights. As an example, the opportunity framework by Muller and Välikangas (2002) enables managers to match the core competences of future partners, as a means to elicit the innovation opportunities related to a strategic alliance.

The why dimension addresses the purpose of a competence visualization, i.e., the managerial or research-related processes supported by it. In particular, the identification process consists of making organizational competences explicit, a primary function which provides the ground work for the subsequent processes. The development process consists of competence exploration, directed at the acquisition of important competences, whereby the organization can close crucial gaps, and strengthen its competitive position. The allocation process consists of competence exploitation, requiring managers to conceive novel uses of the existing competences, in order to leverage a competence for multiple products and across several markets.

Drawing on the above classification, we have developed an integrative framework providing a comprehensive overview on existing (and potential) competence mapping techniques according to their purposes and depiction schemes. As visible in Figure 1, the integrative framework was obtained by positioning the competence visualizations available in the academic literature according to their purpose and form. In the integrative framework, we also include the content (or what dimension) of each of the twelve methods that we have identified. 


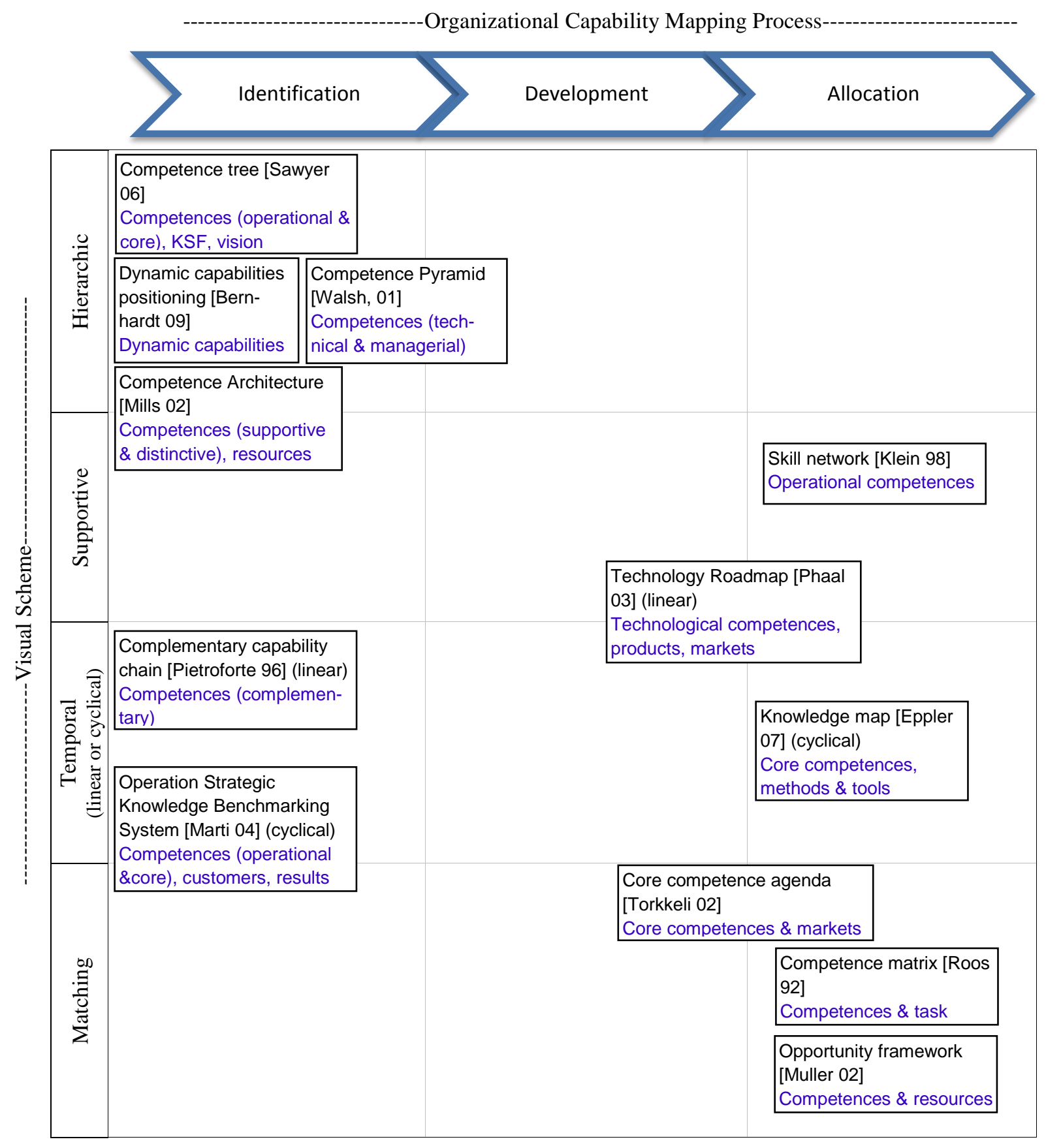

Figure 1: An integrative framework of competence visualizations

For example, the competence architecture by Mills et al. (2002) is a conceptual framework assisting practitioners in identifying organizational competences, along with the underlying resources. Defining competency as a network of resources, Mills et al. (2002) propose to represent competency like a triangle, containing a variety of circles to symbolize resources. As a first step, practitioners identify distinctive competences (i.e., perceivable by customers, such as unique products), and then uncover the underlying resource network. Therefore, practitioners explore supportive competences, which reside deeper in the organization, and provide the implicit ground for strategic resources. As a general rule, the triangle "supportive competence" is drawn with the apex penetrating the triangle "distinctive competence", in coincidence of the most relevant resources. For example, technical competences (e.g., product design and manufacturing process) support the maintenance and development of particular technical resources (e.g., reliable manufacturing system) In a progressive way, practitioners expand on the competence architecture, by drilling down competences, and exploring 
competence-resource relations. In summary, the competence architecture supports the identification process, by connecting competences in a hierarchical order, and showing supportive relations within the resource networks. For example, a competence for working productively within the management team can increase the speed and quality of several activities within a family firm, ranging from operations to customer management.

Intended to support strategic planning, technology roadmapping is a visual technique for mapping and linking technological competences, product developments, and market opportunities (Phaal, Farrukh, \& Mills, 2003). While technology roadmaps are customizable to fit a wide range of organizational contexts, the generic structure is comprised of three layers, and explicitly includes the temporal dimension. The top layer relates to industry trends and drivers, whereas the bottom layer represents the organizational knowledge base. The middle layer acts as a bridging mechanism and relates to the tangible systems developed to address industry trends and drivers, such as engineering processes, operational capabilities, and products. By drawing connections among the three layers, managers explore innovation opportunities, and accordingly plan for competence allocation and development. As depicted in Fig. 2, the visual scheme of technology roadmaps underlines the temporal dimension according to a linear perspective, and displays supportive relations among competences, products, and markets. For example, the founding team of a small architectural practice may identify a shift towards "design and build" contracts in the public sector, whereby the contractor is required to carry out both design and construction work (i.e., industry trends and drivers). In order to exploit this opportunity, the founding team may identify a need to engage in a strategic relationship with a construction company (i.e., bridging mechanism). By leveraging their respective organizational knowledge bases, the partners could pull together the complementary competences and resources needed to deliver integrated solutions.

The skill network by Klein et al. (1998) enables an organization and its members to understand competences as a network of interrelated skills. It allows them to visualize the dynamics whereby skills flow through an organization to create a product advantage. The skill network builds upon the systematic analysis of competence data, collected via structured interviews with organizational informants. In particular, the diagram is produced by applying a mathematical technique to compute what skills contribute the most to product development, and the extent to which skills tend to be used in combination. Graphically, the diagram represents skills as triangles, and skill connections as straight lines converging in a broader network. In this regard, the visual scheme emphasizes supportive relations among skills, and serves the purpose to allocate or communicate competence data across the entire organization. According to Klein et al. (1998), while numeric data can easily lead to detail views, the corresponding visualization can convey the big picture, and build up greater commitment.
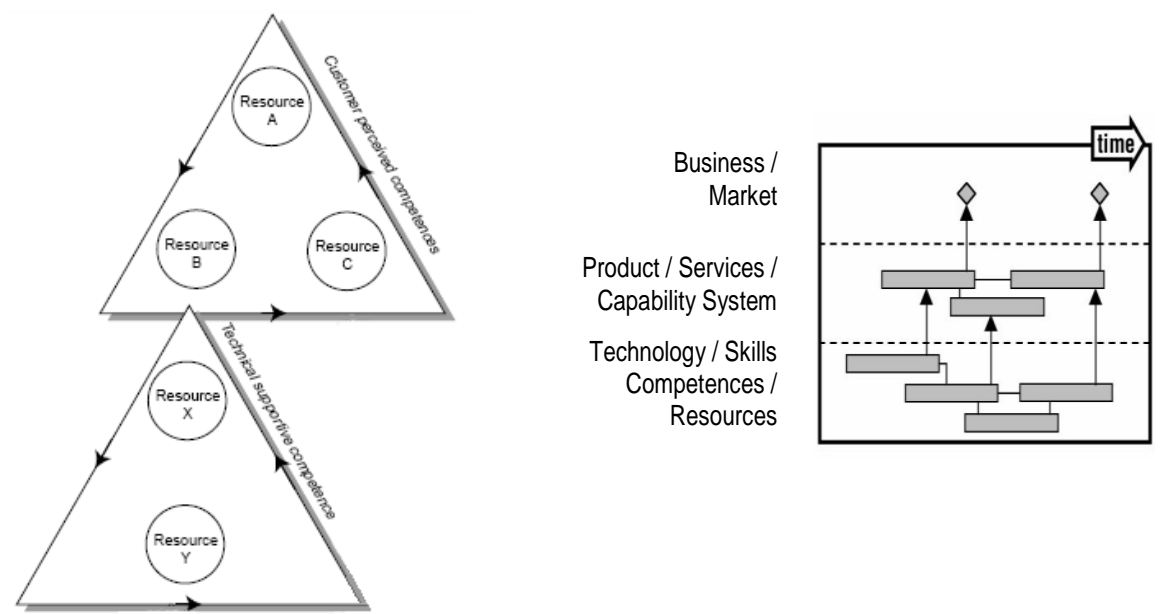

Competence Architecture (Mills et al. 2002) Technology Roadmap (Phaal et al. 2003) 


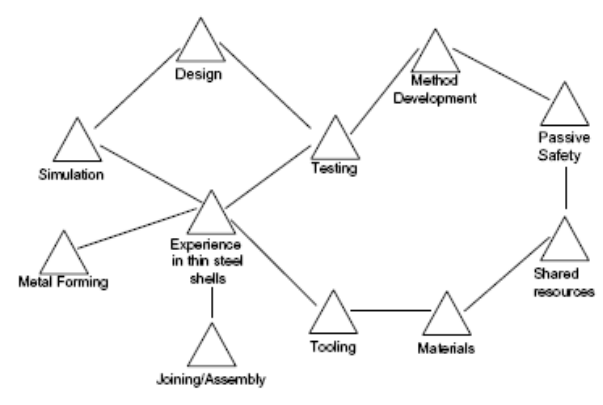

Skill Network (Klein et al. 1998)

Figure 2: Select methods for organizational competence visualization

By taking a general view at the integrative framework (Fig. 2), it is possible to draw tentative associations between the visual schemes and the mapping processes served by competence visualizations. While the competence mapping methods reported in Fig. 2 differ substantially with regard to their aesthetic appearance, consistent patterns can be observed by looking at the individual phases of the mapping process. On occasion, the observation of the collected frameworks provides the starting point to formulate tentative suggestions for the development of novel approaches.

\section{Application: Visually Researching Competencies in a Recently Sold Family Firm}

To illustrate how family firm researchers can use visual competence diagnostic and mapping methods in their research process, we report on the use of two such (complementary) visual templates in a small manufacturing family firm that had been recently sold by the family to new owners, who then became active in the management of the company.

More specifically, we have researched the succession process in this family firm from the founding family to new owners of which one became the new CEO. As it is typical in such a succession process, there was a perceived risk of losing valuable knowledge in the transition (CabreraSuárez et al., 2001). We as researchers were thus asked to assist (among other things) in the task of safeguarding and formalizing the knowledge of the firm and to support the management in the strategy development process. At the time of transition, the family firm had been active in the medical supply industry for approximately sixty years.

The main business of this company was and still is to develop, manufacture and commercialize high-reliability medical devices used by doctors. The company had a solid distribution network and strong partnerships with medical research institutions (mainly for its product development and testing). The competitive advantage of the firm has always been the high reliability and quality of its products and components. But the process by which this high product and component quality comes about often seemed like a black box to the new owners.

To "unpack" this black box and to isolate the family-dependent competencies and resources (such as high employee loyalty, special attention and high care for quality details, special relationships with scientific partners and suppliers in general - all due to personal relations of family members to staff or external partners) from other, more easily replicable capabilities, we as external researchers have employed two competence diagnostic tools, a capability chain and an (abridged) competence tree. These two templates have served as conversation catalysts with the in-house experts and managers of the firm in order to elicit the components or elements of the firm's crucial capabilities (i.e., key activities or resources needed for the competence). Whereas the first method, the capability chain, helped to capture the full range of capabilities along the company's value chain, the second one allowed us to dig deeper into single key capabilities and identify the respective tasks, capabilities, and resources on which they rely. 
Over the course of three months we have used the two templates in one-on-one, face-to-face interviews to identify, structure, and describe the capabilities in this firm. In doing so, we have used empty versions of the templates shown below and asked the company's staff (who were not part of the owning family) to complete them with us or comment on entries made by their colleagues. We have used a digital version of the templates with a facilitation software package called en.letsfocus.com. This has allowed us to replay later on how the template was completed by the experts (i.e., where they changed their mind or modified an initial answer). It also helped to aggregate the findings easily and use them interactively in a larger setting, namely in workshops with the whole management team in a second stage. We have thus used the resulting visualizations in workshops with the entire management team to validate and clarify the identified competencies and their components. This two-step research approach has proven valuable, as potential biases such as social desirability where reduced by first conducting one-on-one interviews, and then presenting the entire management team with the resulting capability maps.

In terms of benefits or results for the organization, this competence diagnostics process has helped the company identify key internal (such as final quality inspections) and external activities (such as client visits) and critical resources (such as brand recognition and awareness, as well as relationships with distributors) as well as potential know-how (loss) risks (in certain technological areas and certain markets). It has also enabled the management team to develop a joint terminology about its competences and thus reduce misunderstandings (especially across functional areas or department borders). In this regard the visualizations also helped the management team to jointly focus on key areas that needed clarification and develop and plan joint measures on how to better manage them in the future. The competence diagnostics also enabled the managers to go back to the founder with more specific questions about the company's know-how and "way of doing things." The fact that the competence diagnostics approach was visual helped the researcher and the staff to work iteratively in refining their (joint) understanding of the company's capabilities and their underlying resources. Instead of writing up a report and having the report individually reviewed, the employed visualizations served as joint sensemaking tools and as conversation catalysts that were refined and revised over the course of several workshops. The visual research also made missing information or inputs more easily detectable and ensured completeness of analysis more than a simple text would have done. If parts of the value chain or competence tree templates remained empty towards the end of an interview or workshop, the researcher was able to focus the staff's attention on these missing or "unfilled" elements and discuss actions to generate more information about these areas of expertise that still needed to be identified or mapped.

For the researcher, the two templates provided a good way to break the ice and create common ground with the informants. The templates served not only as effective elicitation and documentation aids during the interview, but also provided, as mentioned above, an incentive for informant's to revise and improve their contributions while interviewed, as this was easily possible with the software in real-time. Seeing their answers helped the interview partners improve their responses immediately, as they could relate capabilities to each other, adjust the level of granularity as needed, or revise the labeling to better fit their previous answers. In this manner, the template was also conducive to creating a partnership between the researcher and informants to better understand the capabilities of the company. The same iteration and refinement took place in the second stage of the research process, where members of the management team discussed and annotated the aggregated competency maps together.

Figure 3 shows the capability chain template that was used in the first round of interviews to establish an empirical basis for the relevant competencies of this family firm along the value chain. The findings of the value chain critical competences were confidential and we are thus not at liberty to show the completed, real-life diagram. We do show, however, how the template was populated through different example categories and elements. The template was populated in a four step process: In a first step, the researcher asked the staff members to list all the necessary main activities along the company's value chain. In a second step, they were asked to add key capabilities and re- 
sources necessary to complete these activities. In a third step, they had to visually annotate these capabilities and resources with specific situational examples, tools in use, decision or action criteria, or even names of experts in this area inside their organization. In a fourth and final step, the staff members had to color-code or highlight particularly critical elements in the resulting capability chain. They were asked by the researcher, in other words, which elements in the value chain were most at risk to be lost because of the transition in progress. The fact that this exercise was first conducted individually and visually, lead to the opportunity to compare and contrast the different staff members' judgments and perceptions in a subsequent workshop. In a joint session with management and select staff members, the researcher was able to juxtapose the different views on the capability value chain and facilitate a discussion on these differences through an aggregated visualization that showed the different viewpoints in overview.

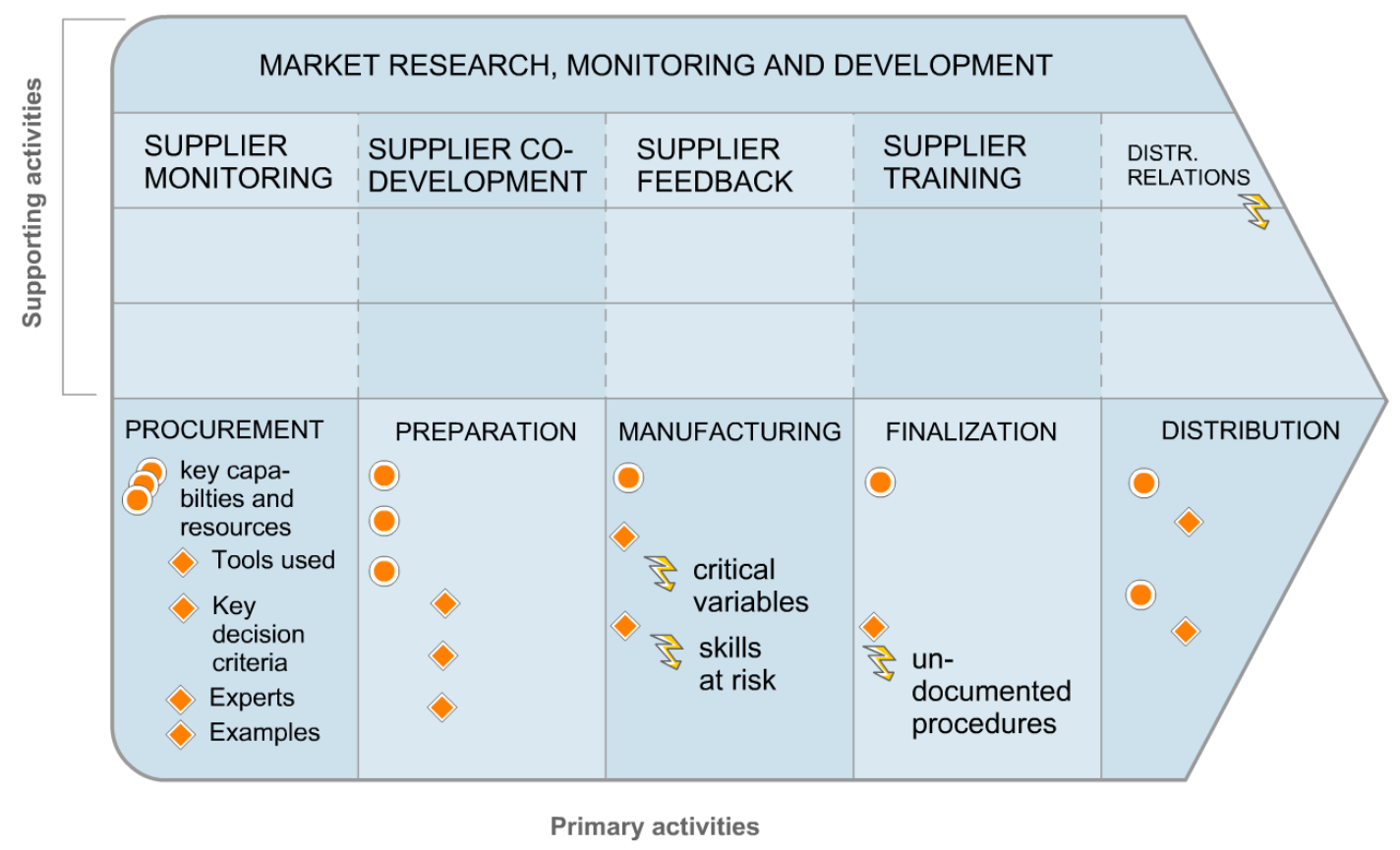

Figure 3: The empty electronic Capability Chain template to gather competencies along the value chain

Figure 4 shows a completed example of a competence tree in order to deepen the researcher's understanding of the perceived elements of one such competence. 


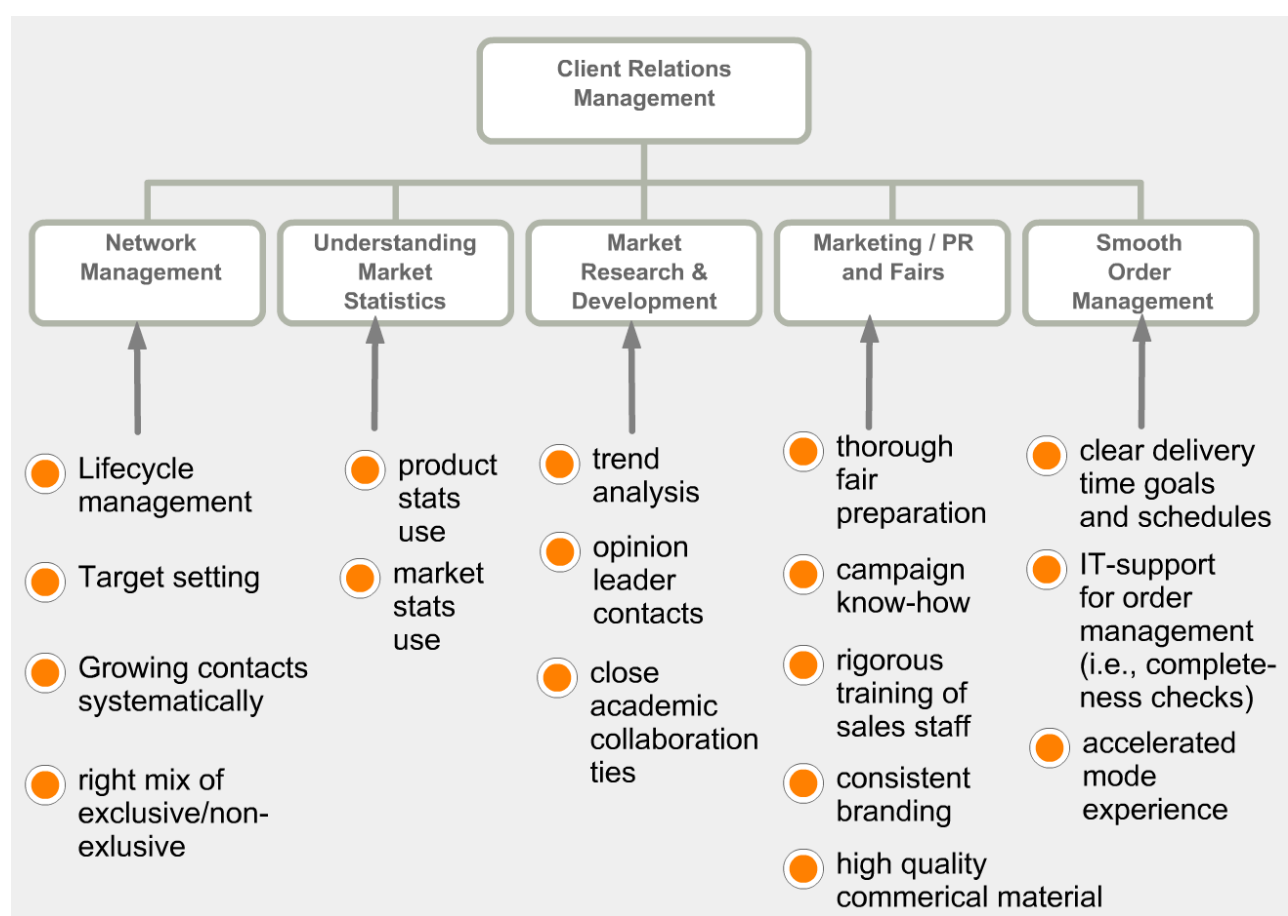

Figure 4: A completed electronic competence tree template to deepen the understanding of a single competency (in this case "client relations management")

Based on this competence tree, the researcher was able to "unpack" the client relations management capability, as it was perceived by management and staff. In a subsequent step, the underlying elements were analyzed in more detail and, whenever possible, properly documented and trained. In this way, a family firm can transform its often implicit knowledge into trainable and documented, robust and safeguarded know-how. It can also detect weak spots in its competence configuration and develop a competence agenda. As the method is visual and the contributions to the tree remain permanently visible to all participants of a competence workshop, there is a propensity to build on contributions made from others and to link competencies in novel ways. Through this, the visual can also lead to new ideas for leveraging or combining competencies in novel way for innovation purposes.

As a key insight from this case study, we can confirm that a genuinely visual approach to researching capabilities has several advantages, especially for family firm contexts: It can help the members of a family firm make the often implicit knowledge base explicit. It can help engage staff members in fruiftful dialogues around these visuals and thus assists them in better understanding the existing and needed capabilities, as well as future development needs and innovation opportunities. Another advantage of the visual approach is the collaborative research atmosphere that the templates help to create. Instead of just "surveying" or observing the subjects, the researcher is engaging the members of a family firm in a constructive, and easily documented (through the completed templates) dialogue.

This experience of using a visual approach to researching a firm and its competences lead to several insights for future knowledge-oriented research endeavors in family firms and SMEs. In fact, we have come to detect certain caveats and success factors when employing visual competence mapping in researching family firms. Specifically, we see the following risks and caveats in using visual methods to research family firm's competencies: A first risk consists of oversimplifying the templates to accommodate the family firm's resource constraints and speedup the interview process. We have sensed this pressure to use simpler versions of the templates, but we advise against this approach as it foregoes the chance to uncover important insights into the family firm's knowledge base. A similar risk consists of over-engineering the visual template and making it too complex for it to serve as a communication device for the managers themselves. If this happens, 
participants' motivation to take part in the research process may be severely reduced. In our experience, the templates can act as boundary (crossing) objects and facilitate joint sense making among members of the firm - if they are not too complicated. The methods we have reviewed in section 2 find, in our view, all a good balance between simplicity and complexity.

In terms of corresponding success factors we believe that it is important to use different, complementary research methods in this context and not rely on one singly mapping method or research technique only (such as solely interviews or focus groups). The capability chain allowed us to examine the entire range of capabilities in this firm, but on a more superficial or general level (which nonetheless surfaced important insights into know-how risks), whereas the competence tree allowed us to research each capability in more depth and detail. This use of different research approaches, however, requires that the firm and its managers trust the researcher and give him or her the freedom to employ different research techniques. And only with trust in and respect for the researcher will they take the necessary time to complete the different templates in the interviews and then validate them in workshops. As often in action research, trust is thus an important success factor for successful investigation. Trust is also important for a final success factor: a clear, consistent and shared terminology. If the company representatives trust the researcher, they are more likely to agree with and profit from his clarification of key terms, such as the distinction among resources, capabilities and (core) competencies. In our experience such a clear "meta-language" is important to formalize the knowledge embedded in a family firm.

\section{Discussion and Conclusion}

Besides its function to synthesize existing approaches, the integrative framework presented in this article provides support to researchers who want to use visual methods for competence identification in family businesses. It facilitates the selection of one or more methods with regard to the task at hand. It also shows where multiple methods are available (such as for competence identification), and where more research is still needed (such as in the competence development area). The integrative framework may also provide general directions for the production of visual templates directed to understanding and managing the competence structure of family businesses.

As a general rule, a competence template must address the three questions underlying the integrative framework (What? How? Why?), in order to effectively support competence identification and/or management. In particular, the researcher should be aware of the fact that different questions require the selection of different methods, to be adapted also to the context of the family business at hand. Furthermore, the classification dimensions may serve as a guideline for the evaluation of current templates, and the identification of areas for future research. As visible in our integrative framework, a large cluster of competence templates supports competence identification by underlying hierarchical relations in the visual scheme. Such templates operationalize the competence concept by suggesting a visual hierarchy in which the competence components are singled out, and connected to the overarching strategy.

Yet current templates suggest a somewhat static depiction of competences, failing to represent the dynamic processes whereby an organization strengthens and adjusts its competence configuration. Future templates should therefore focus on processes by which competences can be combined, rearranged, and exploited. By visualizing possible recombination of existing capabilities, such templates would support the development of exploitative strategies. Moreover, the visual representation of coordination mechanisms should be further explored, beyond the sketchy categories currently reported under the How dimension. For example, a future template may capture the knowledge intensity of the coordination mechanisms needed for managing competences. Knowledge-intensive coordination is required to recombine competences for innovation purposes, while routinely-based coordination enables the connection of resources and competences for ordinary procedures.

The integrative framework thus presents the dual advantage of synthesis and scalability, meaning that it captures existing methods, and that it can be used to better understand the function of (or 
need for) future ones. Further analysis, however, is needed for the integrative framework to reach the maturity stage. At present, it is subject to an ongoing revision, and the underlying dimensions are checked and eventually refined against the addition of further elements. In future research, we will perform surveys among researchers and practitioners to assess to what extent the competence visualizations really support the processes indicated in the framework (as claimed by the respective authors).

As a main implication for family researchers who wish to employ visual approaches in their research endeavours, we emphasize the potential of including visual templates throughout all stages of a research process. Too often, visuals are only seen as accessible ways to represent research findings on family firms, and not as catalysts to generate insights into a family firm. In their exploration of absorptive capacity of a family-owned airline, Boyd and Hollensen (2012) used a visual representation (i.e., a competence pyramid) to display the results of their data analysis, but not to facilitate the interview process. Perhaps the use of visual methods in the stage of data collection could have assisted participants in the identification of the connections between personal and corporate competences, thereby leading to a more detailed map of the competence structure underlying Cumber's competitiveness. This is an important prerequisite for theory building, as it helps to uncover novel patterns that may have gone unnoticed in previous studies and that separate family businesses from other types of organizations (from a resource-based perspective). In doing so, family business researchers must, however, pay attention to certain caveats. They should steer clear of oversimplifying the graphic representation of a competence configuration of companies that they study, while still allowing their representations to be useful to the family business managers themselves. It is not always easy to find the balance among the two extremes. For that it may be necessary to use more than one competence template (and more than one version of each). As our case example showed a typical combination may include one approach that enables the researchers to cover the breadth of competences, whereas another may help him or her to deepen the understanding of a single competence of a family firm. We see the greatest advantage for theory building in the fact that these visual approaches help researchers to stay rooted in the concrete activities of the family firm members and restrict the "abstracting away from reality" that sometimes goes hand in hand with theory building. Through the visual approaches outlined in this article, we hope that family firm researchers can draw distinctions that are not only theoretically relevant and empirically grounded, but also matter to practitioners.

\section{References}

Astrachan, J. H. (2010). Strategy in family business: Toward a multidimensional research agenda. Journal of Family Business Strategy, 1(1), 6-14.

Astrachan, J. H., \& Kolenko, T. A. (1994). A neglected factor explaining family business success: Human resource practices. Family Business Review, 7(3), 251-262.

Bakker, H., Jones, W., \& Nichols, M. (1994). Using core competences to develop new business. Long Range Planning, 27(6), 13-27.

Baum, J. A. C., Calabrese, T., \& Silverman, B. S. (2000). Don't Go It Alone: Alliance Network Composition and Startups' Performance in Canadian Biotechnology. Strategic Management Journal, 21(3, Special Issue: Strategic Networks), 267-294.

Bell, E., \& Davison, J. (2013). Visual Management Studies: Empirical and Theoretical Approaches. International Journal of Management Reviews, 15(2), 167-184.

Bresciani, S., \& Eppler, M. J. (2009). The Benefits of Synchronous Collaborative Information Visualization: Evidence from an Experimental Evaluation. IEEE Transactions on Visualization and Computer Graphics, 15(6), 1073-1080.

Cabrera-Suárez, K., De Saá-Pérez, P., \& García-Almeida, D. (2001). The Succession Process from a Resource- and Knowledge-Based View of the Family Firm. Family Business Review, 14(1), 37-46. 
Carlile, P. R. (2004). Transferring, Translating, and Transforming: An Integrative Framework for Managing Knowledge across Boundaries. Organization Science, 15(5), 555-568.

Carmeli, A. (2004). Assessing core intangible resources. European Management Journal, 22(1), $110-122$.

Chirico, F., \& Nordqvist, M. (2010). Dynamic capabilities and trans-generational value creation in family firms: The role of organizational culture. International Small Business Journal, 28(5), 487-504. doi: 10.1177/0266242610370402

Chrisman, J. J., Kellermanns, F. W., Chan, K. C., \& Liano, K. (2010). Intellectual foundations of current research in family business: An identification and review of 25 influential articles. Family Business Review, 23(1), 9-26.

Clark, D. N. (2000). Implementation issues in core competence strategy making. Strategic Change, 9(2), 115-127.

Eden, C., Williams, T., Ackermann, F., \& Howick, S. (2000). The role of feedback dynamics in disruption and delay on the nature of disruption and delay (D\&D) in major projects. Journal of the Operational Research Society, 51(3), 291-300.

Gallon, M. R., Stillman, H. M., \& Coates, D. (1995). Putting core competency thinking into practice. Research Technology Management, 38(3), 20-28.

Habbershon, T. G., Williams, M., \& MacMillan, I. C. (2003). A unified systems perspective of family firm performance. Journal of Business Venturing, 18(4), 451-465.

Habbershon, T. G., \& Williams, M. L. (1999). A resource-based framework for assessing the strategic advantages of family firms. Family Business Review, 12(1), 1-25.

Javidan, M. (1998). Core competence: what does it mean in practice? Long Range Planning, 31(1), 60-71.

King, A. W., \& Zeithaml, C. P. (2001). Competencies and firm performance: examining the causal ambiguity paradox. Strategic Management Journal, 22(1), 75-99.

Klein, J., Gee, D., \& Jones, H. (1998). Analysing clusters of skills in R\&D: core competencies, metaphors, visualization, and the role of IT. $R \& D$ Management, 28(1), 37-42.

Le Breton-Miller, I., \& Miller, D. (2006). Why Do Some Family Businesses Out-Compete? Governance, Long-Term Orientations, and Sustainable Capability. Entrepreneurship Theory and Practice, 30(6), 731-746.

Lewis, M. A. (1995). Competence analysis and the strategy process. Cambridge: University of Cambridge, Cambridge, PhD thesis.

Liu, W. (2006). Knowledge exploitation, knowledge exploration, and competency trap. Knowledge and Process Management, 13(3), 144-161.

Marino, K. E. (1996). Developing consensus on firm competencies and capabilities. The Academy of Management Executive, 10(3), 40-51.

Marti, J. M. V. (2004). Strategic knowledge benchmarking system (SKBS): a knowledge-based strategic management information system for firms. Journal of Knowledge Management, $8(6), 31-49$.

Mazzi, C. (2011). Family business and financial performance: Current state of knowledge and future research challenges. Journal of Family Business Strategy, 2(3), 166-181.

Mills, J., Platts, K., Bourne, M., \& Richards, A. (2002). Competing through competences: Cambridge University Press.

Muller, A., \& Välikangas, L. (2002). Extending the boundary of corporate innovation. Strategy \& Leadership, 30(3), 4-9.

Narula, R. (2004). R\&D collaboration by SMEs: new opportunities and limitations in the face of globalisation. Technovation, 24(2), 153-161.

Penrose, E. T. (1995). The Theory of the Growth of the Firm: Oxford University Press.

Phaal, R., Farrukh, C. J. P., \& Mills, J. F. (2003, 2003). Customizing the technology roadmapping approach. Paper presented at the Proceedings PICMET 2003. 
Pietroforte, R. (1996). Building international construction alliances - Successful partnering for construction firms. Boundary Row, London: E \& FN Spon.

Prahalad, C. K. (1993). The role of core competencies in the corporation. Research Technology Management, 36, 40-40.

Prahalad, C. K., \& Hamel, G. (1990). The core competence of the corporation. Harvard Business Review, May-June, 79-90.

Rulke, D. L., Zaheer, S., \& Anderson, M. H. (2000). Sources of managers' knowledge of organizational capabilities. Organizational Behavior and Human Decision Processes, 82(1), 134-149.

Sawyer, K., \& Gammack, J. (2006). Developing and analysing core competencies for alignment with strategy. International Journal of Knowledge Management, 2(1), 58-71.

Sharma, P., Chrisman, J. J., \& Chua, J. H. (1997). Strategic Management of the Family Business: Past Research and Future Challenges. Family Business Review, 10(1), 1-35.

Sirmon, D. G., \& Hitt, M. A. (2003). Managing Resources: Linking Unique Resources, Management, and Wealth Creation in Family Firms. Entrepreneurship Theory and Practice, 27(4), 339-358.

Snijders, J., van Lin, M., \& van der Horst, R. (2003). Competence Development in SMEs. In S. Jacqueline, v. L. Micha \& v. d. H. Rob (Eds.), 2003 Observatory of European SMEs. Luxembourg: European Commission.

Tampoe, M. (1994). Exploiting the core competences of your organization. Long Range Planning, 27(4), 66-77.

Torkkeli, M., \& Tuominen, M. (2002). The contribution of technology selection to core competencies. International Journal of Production Economics, 77(3), 271-284.

Vaitkevičius, S. (2006). Modelling of strategic analysis in strategic management. Engineering Economics(4 (49), 37-47.

Van de Ven, A. H. (2007). Engaged Scholarship: A Guide for Organizational and Social Research: Oxford University Press.

Walsh, S. T., \& Linton, J. D. (2001). The competence pyramid: a framework for identifying and analyzing firm and industry competence. Technology Analysis \& Strategic Management, 13(2), 165-177.

Webb, J. W., Ketchen Jr, D. J., \& Ireland, R. D. (2010). Strategic entrepreneurship within familycontrolled firms: Opportunities and challenges. Journal of Family Business Strategy, 1(2), 67-77.

Winter, S. G. (2003). Understanding Dynamic Capabilities. Strategic Management Journal, 24(10, Special Issue: Why Is There a Resource-Based View? Toward a Theory of Competitive Heterogeneity), 991-995.

Yang, B.-C., Wu, B.-E., Shu, P.-G., \& Yang, M.-H. (2006). On establishing the core competency identifying model: a value-activity and process oriented approach. Industrial Management \& Data Systems, 106(1), 60-80.

Zahra, S. A., Hayton, J. C., \& Salvato, C. (2004). Entrepreneurship in Family vs. Non-Family Firms: A Resource-Based Analysis of the Effect of Organizational Culture. Entrepreneurship Theory and Practice, 28(4), 363-381. 